\title{
Alcoholism: A social deadly disease of the society
}

\author{
Johnson Adetunji Olanipekun \\ Department of Human Kinetics and Health Education, Ekiti State University, Ado-Ekiti, Nigeria
}

Email address:

jaolanipekun@gmail.com

\section{To cite this article:}

Johnson Adetunji Olanipekun. Alcoholism: A Social Deadly Disease of the Society. American Journal of Life Sciences. Vol. 2, No. 5, 2014, pp. 312-318. doi: 10.11648/j.ajls.20140205.20

\begin{abstract}
Alcoholism as a lightning has become a major deadly social disease of the society. Many lives and properties have been lost and many have been permanently deformed as a result of heavy consumption of alcoholic drinks. This paper therefore, examined the concept, patterns, types of and psycho-social reasons for alcoholism. The paper also investigated the dimensional problems or consequences associated with alcoholism as a deadly disease. It discussed the treatment of alcohol drinking problems and the role of health educators as regards alcoholism. Towards its reduction in the society, it is therefore, recommended that mass education on alcoholism should be encouraged, health education should be made a compulsory subject for all students in all educational institutions, and there should be a formation of Alcoholics Anonymous group for the peers or young in the society.
\end{abstract}

Keywords: Alcohol, Alcoholism, Binge Drink, Alcoholics, Health Educators, Alcoholic Beverages

\section{Introduction}

People have been drinking alcoholic beverages from time immemorial. Globally, alcohol is the most widely used mindaltering substance. Alcoholism has become a deadly social disease in the society because it can produce harmful effects when excessively consumed. Afterwards, the habit of drinking alcohol does not promote growth and development of the drinkers. Many people have lost their lives and properties in accidents and deformed due to heavy alcoholic drinks which contain ethanol. Any liquid containing 0.5 to $0.80 \%$ ethyl alcohol is an alcoholic beverage (Nelson, 2005). Despite its side-effects on human body, it also has some beneficial qualities on heart and circulation most especially the red wines when they are moderately consumed (Geddes and Grosses, 2001). For instance, it reduces the risks of clot formation and help to prevent high blood pressure, heart attacks and angina, enhances social interactions, increases the enjoyment of food, induces pleasant feelings, help a person to relax with appreciative caloric values as a food and cope with the minor stresses of daily life, stimulates the flow of gastric juices and also useful sedative (Hussell, Fifield and Brimble, 1998; Geddes and Grosses, 2001; Jancin, 2003; Havard, 2003).

Despite its beneficial qualities, experience has shown that alcohol has been responsible for much misery in the world, because some people over-indulge in its effects. Alcoholic beverages are poisonous substances to the body systems that should never be drunk. Usually alcoholic people, repeatedly use alcohol as more than the usual accomplishment to eating or beyond the ordinary social customs of the community (Dianne, 2007). Alcohol as a psycho-social depressant drug is consumed in several forms (Mintz, 2012). It is a depressant drug because with increasing doses, it puts to sleep various parts of the brain and nervous system- to a point where given extra large doses may result to death. However, the quantity, quality, rate and speed of alcohol we take, the food content in the stomach, the environment we are, the physical and emotional status of the drinker and his expectations determine the effects of alcohol in the body systems.

Before the introduction of western world or European alcoholics' drinks like beers, wines, and spirits. Most drinkers in Nigeria consumed the traditional alcohol beverages such as palm-wine, burukutu, pito, apetesi and wines (Briggs,2010). These local drinks in addition to beer and spirit have remained valuable and popular till today in various social settings.

Experience has shown that many people most especially the youths, have become socially interested in alcohol beverages that they cannot do without it, forgetting that this habit does a greater harm than good in the body systems. However, one may wonder whether or not drinking of alcoholic beverages is harmless for both young and old but, studies revealed the facts that the persistent use, misuse and 
abuse of alcohol as harmful substances to the body systems. (Dianne, 2007; Moore, 2009; Briggs, 2010). Thus, there is need to help modify peoples' attitudes to the consumption of alcoholic beverages, thereby reducing anti-social behaviours among youths such as armed robberies, kidnapping, raping, human killing, and disrespect to constituted authorities in the society.

\section{Concept of Alcoholism}

Alcoholism is primarily chronic and progressive deadly social disease related to continuous consumption of alcoholic drinks, and in which genetic, psychosocial and economical and environmental factors are correlate to its development and manifestations (Office of Applied Studies, Substance Abuse and mental Health Services Administration, 2002 and Whitey, 2009). Globally, alcoholism seems to be number one drug problem in the United States and in many other nations (Wechsler, 1994). This lethal colourless ethanol is obtained through the fermentation of a liquid containing sugar at a particular degree to determine the level of its alcohol content (Jane, 2010). Alcoholism as a chronic illness portrays a progressive disorder of behaviour and fatal social disease often characterized mainly by uncontrollable alcohol drinking. This interferes with the major aspects of the victim's daily endeavours. The victim is called alcoholic or compulsive drinker. As a social disease, the alcoholic becomes unable to control the time, enjoy poor judgment, coordination and quantity of his drinking and irrational thinking and behaviours. Thus, issues related to personal responsibility, family roles, job and health become relatively unimportant to the alcoholics.

It appears that the use of alcoholic beverages is as old as man. Alcoholism generally appears under fifty years most especially in adolescence and early adulthood (Granty and Dawson, 2007). Children of alcoholics are more likely to suffer abuse of other harmful substances, enjoy psychological or emotional problems, become alcoholics and have many alcoholic peers. Although, it is not illegal in most countries, it is very powerful drug which can be extremely dangerous. In the United Kingdom in 1988, 1000 young people died from the effects of heavy consumption of alcohol beverages compared with 100 who died from using hard drugs (Jane, 2010). Like other diseases, alcoholism is simply a matter of insufficient will-power and a complex social problem that resulted to many symptoms with serious physical, occupational, psychological, sociological and spiritual consequences.

The Old Testament and the writings of the Greeks, Romans, Chinese, Japanese and Indians denounced excessive drinking of alcohol (Jones, Shainberg and Byer, 2009). In Nigeria colonial history, alcohol drinking was accepted but drunkenness was punished by fines, whipping and confinement in the stocks. The early temperance movement focused on an appeal for moderation that permitted the use of beer and wine, but urged abstinence from distilled spirit. However, alcohol was abandoned because of the bootlegging of illicit liquor, and anti-social vice related to it. A regular and moderate consumption of alcohol beverages became socially acceptable, although many people still feel that total abstinence is desirable. Heavy intake of alcoholic beverages has been attributed to many miseries in the world, because some people over- indulged in its effects.

Alcohol does not have to be digested but absorbed by the body. It can pass directly into the blood stream from the stomach or intestine. This increases the amount of alcohol in the blood of the alcoholics at any given time (Blood Alcohol Concentration-BAC). This is expressed in term of the percentage of alcohol in the blood and in often measured from breath or urine samples (National Institute of Alcohol Abuse and Alcoholism, 1999). The Law Enforcement officers use BAC to determine whether a driver is legally drunk. Many factors such as the rate, quantity and quality of alcoholic beverage consumed, somatotyping, gender; age; race; other drugs; family history of alcoholism; eating and expectations determine the individual's BAC and response to alcoholic beverages (Mulamai, 2009).

\section{Epidemiological Patterns and Trends of Alcoholism}

Although heavy alcoholic beverage consumption is generally considered a personal and private issue, its effects permeate all sectors and dimension of the society. Alcohol consumption has been a constant component of man's life from time immemorial. Attempt to control, restrict, or abolish alcohol in the developed, developing and underdeveloped world have all met with failure (Office of Applied Studies, US Department of Health and Human Services, 2007). Drinking behaviour is most likely to occur among men and women under 50years of age, of higher social status, professionals, non-professionals, technical workers and management officials, college and university students and graduates with binge drinking, single men and women, residents of suburban cities and towns, those whose father were foreign-born, those whose parents drinks or approved of it and also with peers who are heavy drinkers. Others regular consumers of alcoholic beverages are operatives and service workers, out of school students, divorced or separated men and women and those without any religious affiliation.

Chronic alcohol abuse or alcoholism usually manifest itself due to daily intake of large amount of alcohol, regular heavy drinking on weekends and periodic heavy binge drinking for weeks or months. Clinical diagnosis of alcohol is based on symptoms persisting for a month or more, or occurring repeatedly over a period of time (Geddes and Grosset, 2001). Such symptoms include alcohol intake in large amount(5 or more in a day), persistent desire to quit drinking, considerable time spent obtaining alcoholic drinks, using or recovering from alcohol, persistent drinking despite social, psychological or physical symptoms, sleep problem, denial of an alcohol problems, loss of memory, depression and desire for a drink to start a day. Others are poor judgment, 
imbalance, headache, stomach pain, fatigue and weakness, muscle cramp and irregular or rapid heart rate (Baer, 2004).

Alcoholism is associated with different patterns of drinking alcoholic beverages (National Institute on Alcohol Abuse and Alcoholism, 1999). The most common and generally recognized patterns of consumption of alcoholic drinks among young men, especially those who are single, separated, or divorced, who drink beer, or who concentrate most of their drinks on weekends include light, infrequent, moderate, social, problem and binge drinking (Dianne, 2007).

In another dimension of alcohol drinking pattern, Office of Applied Studies, Substance Abuse and Mental Health Services Adminkistration (2002) and Mulamai (2009) reported that those who never drink with the exception of consuming communion wine in religious ceremonies are non-drinkers with non-drinking pattern. The social drinkers are distinguished by their control over the quantity and rate of consumption and their ability to choose whether to engage in such social activity. Thus, they follow social drinking pattern. They have a range of drinking behaviours such as light, moderate and heavy. They reject drinking by certain persons in various circumstances as inappropriate, and they themselves are subjects to peer group sanction, laws and ordinances against anti-social behaviours resulting from alcohol misuse and abuse. The episodic excessive drinking pattern involves the use of alcoholic beverages sometimes exceeds social norms and results in intoxication. Such persons follow progressive excessive drinking pattern with drinking episodes becoming more frequent and periods of intoxication lengthen. Physical disorders, deterioration of social relationships, and difficulties with the law enforcement agencies become apparent. People with chronic alcoholic drinking pattern have developed a drug dependency in which the control over the quantity and frequency of drinking is lost. Their persistent alcohol abuse is marked by severe physical disabilities, impaired social and economic relations, and sometimes frequent acts of public intoxication.

\section{Types of Alcoholism}

In the past, Bier (1962) identified two primary types of alcoholics as Type I or milieu-limited and Type II. Type I alcoholics generally start heavy drinking after age 25 , often in response to setbacks, looses, or other external circumstances. They possess personality traits such as shyness, anxiousness, emotionally dependence, rigid, loss of control, guilt and fear, and slow to anger. Since alcohol reduces their anxiety level, it serves as a positive rein-forcer for continuous use and contributes to the development of alcohol dependence.

Type II alcoholics become heavy drinkers before age 25 . They drink regardless what is going on in their lives and have frequent fights and arrests. They do not usually experience guilt, loss of control over their drinking. However they are impulsive and aggressive risk-takers, curious, excitable, quick-tempered, optimistic and independent. Alcohol reinforces their feelings of euphoria, pleasant excitement and often abuses other drugs.

Recent studies on alcoholism considering gender issues classify it as Type A or Type B (Baer, 2004; Archer, 2005; Mukamai, 2009). Type $A$ alcoholism is a milder form, characterized by onset later in life, fewer childhood risk factors, less severe dependence, fewer alcohol-related physical and social consequences, symptoms of other mental disorders and less interference with work and family. Type B alcoholism is linked with childhood and familial risk factors, begins at an earlier age, leads to more serious consequences, and often occurs along with other mental disorders. They are more anxious and inclined to experiment with other drugs and of lower occupational status than Type $A$ alcohol.

\section{Determinants of Alcoholism}

There is no single cause of alcoholism, just as there does not seem to be one kind of alcoholism. However, naturally, there are many determinants responsible for alcohol problems of which the major ones are mentioned below

\subsection{Family History}

Certain factors include hereditary, family cultural acceptability of heavy alcohol consumption and cases of stress in a family all seem to play a leading role. Family history of alcohol problems may increase man's risk for alcoholism. There is also a significant association between alcoholism in people who were adopted and their biological parents (National Institute of Alcohol Abuse and Alcoholism, 1999). Studies showed that more than $40 \%$ of who initiated drinking before age 15 was considered alcohol dependent at a stage in the lives. Women who were sexually, verbally or physically abused in a family also reported with more alcohol related problems. (Granty and Dawson, 2007). Scientists believe that alcoholism runs in families because it is a learned behaviour by watching the people around them on how they use, misuse and abuse alcohol. Studies revealed that alcoholic parents tend to produce young who tends to drink heavily. Parents with moderate drinking habits produce moderate drinkers and that abstainers produce children who tend to abstain (Wechsler, 1994; Wetherington, 2008; Korolenko and Donrieih, 2010). Others assume that there is a biochemical defect in alcoholic people that does not permit them to handle alcohol in a normal way.

\subsection{Cultural Dimension of Alcoholism}

Cultural factors influence the prevalence of alcoholism because of the natural acceptance of alcohol consumption in a family and community rituals, initiation ceremonies and other social rites.

\subsection{Region and Educational Level}

Alcohol consumption rate also varies by region and level of education. People in the North central region, South-west, South- East, and South-South in Nigeria involve more in the heavy consumption of alcohol use when compared with their 
North-East counterparts (Mulamai, 2009 ).Experience has shown that individual with higher level of education tends to be moderate drinkers more so than those who are less educated (Korolenko and Donrieih, 2010).5.4. Psycho-social Dimension of Alcoholism

Social phenomena contribute to alcohol consumption and influence access to recovery service. Society double standard for women certainly prevails where alcoholism is concern. The popular media and folklore portrays a male drunk as comical and lovable, but a drinking woman as loose, weak and immoral. This double standard extends into the treatment arena. This great social sanction makes some women less willing to seek help and other willing to recognize that they need help. In addiction, alcoholic woman violates the stereotype of feminine behaviour and distress their families and friends and even the health professionals who might support them.

People who consume alcohol heavily think that alcohol is a stimulant because it seems to make them feel free, seek relief from stress or relax, have fewer inhibitions than they had before taken alcohol. Traits associated with alcoholism also include history of anti-social behaviour, high level of depression, and low-self esteem. However, one can say the probable causes of alcoholism include distress, social or peer group pressure, public occupation, fear, anxiety, success, escape from reality, feeding and even as medicine.

Other motivations for drinking alcoholic beverages to the extent of abusing it and resulting to alcoholism include celebrations that involve ethic, religious values, life's important occasions such as births, graduations, weddings, house warming, promotion or achievement; friendship, social ease, self medication and even role models and media advertisement.

\subsection{Gender-based Dimension of Alcoholism}

Gender-based social norms often contribute to alcohol consumption patterns. For example, in some cultures, men are drinkers while women generally abstain. Gender may engage in compensatory drinking consuming alcohol to heighten their sense of masculinity or femininity (Wechsler, 2011).

\subsection{Victimization and Alcoholism}

Victimization is another factor associated with alcoholrelated problem. Victimization is often leads to depression, which in turn is associated with alcohol use. Physical abuse as an adult is also a factor that may increase man's risk for alcohol abuse or dependence. Studies revealed that women who reported being sexually abuse in childhood were more likely to experience alcohol related-problems as adult (Wilnack, Vogeltanz and Klasser, 1997). Experience has shown that lesbian women consume more alcohol for longer periods and may be at greater risk of alcohol problems because of the social disapproval directed at their sexual orientation and social environment. They are more likely than heterosexual women to use alcohol in combination with other drugs (Brewer and Monica, 2006; Wetherington, 2008).

\section{Legal issues of Alcohol \& Alcoholism}

There are many legal issues that are related to alcohol drinking. Legally and nationally, alcohol use is limited to people older than age 21 . In most other countries, no such age limit exists. In many Islamic countries such as Saudi Arabia and partly Northern States in Nigeria, however, alcohol use remains illegal. In addition to setting age limit on alcohol use, laws are enacted to govern drinking and driving, drunk and disorderly behaviours, purchase of alcohol, and driving with an open container of alcohol (Geddes and Grosses, 2001). These laws limit how and when individual can consume alcohol. The penalties associated with alcohol abuse or more involve fines or charges, and even entail mandatory jail time in many countries of the world (Wehterington, 2008; Korolenko and Donrieih, 2010 and Wechsler, 2011).

\section{Side-Effects of Alcoholism}

When an alcoholic drinks too much, the immediate consequence is that he gets drunk, or more formally, intoxicated. Intoxication consists of clinically significant maladaptive behavioural changes, such as inappropriate sexual or aggressive behaviour, mood changes, and impaired judgment and social and occupational functioning (Fleming, 2005; Moore, 2009). Alcohol intoxication is characterized by slurred speech, poor coordination, unsteady gait, abnormal eye movements, impaired attention, or memory and stupor, or coma. The medical risks of intoxication include falls, hypothermia in cold climates, and increased risks of infections because of suppressed immune function (Baer, 2004).

Alcoholic beverages serve as a central nervous system depressant that effectively impairs all major body systems. Heavy drinking of alcoholic beverages may lead to hepatitis, which is characterized by inflammation and destruction of liver cells and cirrhosis; which produces progressive scarring of liver tissues (Baer, 2004). Chronic consumption of alcohol has adverse effect on the immune system by increasing susceptibility to infections such as pneumonia and tuberculosis. It also affects the brain cells by damaging them; impair perception, judgment and motor cells.

Heavy drinkers' white blood cells capacity to fight infection is decreased and cause anemia and interfere with blood clotting and even resulted to cancers, diminished perception of pain and temperature, inflammation of the pancreas, increased risk of osteoporosis and stroke. Additional drinking of alcohol results in a progressive reduction in a behavioral activity. This may lead to sleep, general anesthesia and even untimely death (Archer,1995; Baer, 2004; Mintz, 2012).

Alcohol is particularly dangerous to reproductive tract causing birth defects and may lead to gynecological and obstetrical problems. Heavy alcohol consumption typically 
leads to several nutritional problems for the economic user. Alcohol dulls the senses of taste and smell which makes heavy drinkers often skip meals and develop nutritional deficiencies, diarrhea, gastritis, peptic ulcer, alcoholic pellagra, polyneuropathy, constipation and even fatigue (Wechsler, 2011; Mintz, 2012). Experience has shown that, moderate amounts of alcohol can have disturbing effects on perception and judgment, including impaired perception, dulled smells and taste, diminished sensation, altered sense of space, impaired motor skills and sexual performance.

Children of alcoholic parents are vulnerable to learning disabilities, eating disorders, and additive behaviour. Adult children of alcoholic parents are more likely to have difficulty in solving problems, identifying and expressing their feelings, trusting others, and being intimate. They may develop some forms of addiction themselves, or marry someone with additive patterns. Individuals with additive behaviours or dependence on alcohol, and the children or partners of such people are likely to find themselves in dysfunctional relationship that do no promote healthy communication, honesty, and intimacy.

\section{Alcoholism and Society}

Globally, the economic, social \& personal cost of alcohol related problems among heavy drinkers include crimes or violence, accidents illnesses, neglect of family obligations, poverty, dependency, insanity, invalidism and death. Alcohol consumption contributes to sufficient morbidity and mortality among races worldwide (Baer, 2004). It uses is associated with more than $45 \%$ of all motor vehicle crash fatalities, roughly $1 / 3$ of homicides and suicides and $22 \%$ of all other fatal accidents (National Institute on Alcohol Abuse and Alcohol, 1999). Whitey (2009) reported that alcoholism amount for $0.8 \%$ all death and the life of alcoholism is 10 to 12 years below the average.

It has been observed that alcohol reduce output and lessens caution, skill, endurance and accuracy. In many industries, production is lowered and avoidable accidents are increased. It has been found that alcoholism predisposes a person to many industrial poisons. Alcoholism costs bad executive decision, low morale and poor public relations. The effects of alcohol upon the accident rate in the industrial sectors are also apparent (Jane, 2010). Almost 70\% of the costs of alcohol abuse are related to lost productivity-45\% to alcohol related illness and $21.2 \%$ due to premature death. In addition, underage drinking cost more than \$70billion per year (Wechsler, 2011). The social consequences of heavy drinking are related to the character, nervous instability and physical traits of the drinkers. It has been observed that alcohol reduce output and lessens caution, skill, endurance and accuracy. In many industries, production is lowered and avoidable accidents are increased. Issues related to such offences of drunkenness as pubic intoxication, vagrantly and disorderly rape, assault and child abuse are highly connected to alcoholism.

Experience has shown that a devastating effect of alcohol upon morals, marriage, family life and sexual promiscuity are more prevalence after drinking because normal inhibitions are lower. It has been estimated that three quarter of the cases of sexually transmitted infection (HIV/AIDS) have been reported while the persons were under the influence of alcohol (Mintz, 2012). The chances of a successful marriage have been shown to have reduced and the probably divorce increased among alcoholic parents. Drinking has kept many families on poverty. Society pays a high price for using alcohol. Excessive drinking destroys the personal traits which results to loss of self-control, lack of respect to other people, and of self-respect. Men and women who drink too much often run away from unpleasant facts in their lives. However, drinking does not solve problems, it creates them. The death rate aiming women alcoholism is higher than the male alcoholics because women alcoholics have an increased risk for suicide, various sexual immoralities, alcohol-related accidents, cirrhosis, and hepatitis (Wethrington, 2008).

\section{Strategies for the Prevention of Alcoholism}

Prevention against alcoholism include the development of coping strategies and learning techniques that make it easier to live with alcohol cravings and rehearsal of various ways of saying "no" to offer an alcoholic beverage. The use of social skills training has proven effective in decreasing the duration and severity of relapses (Wechsler, 2011; Mintz, 2012).The relapse prevention strategies involve the following:

1. Participation in recreational exercises which provide an outlet for aggression, enhances of self-image, and reduces mild depression.

2. There should be life-style changes, including developing a network of non-drinking friends; removing alcohol from the house; and avoiding highrisk situations such as stopping at a bar.

3. Refusal training; rehearsing various ways of saying "No". A simple "Thank you, but I've had enough" will do.

4. Stress reduction to ease the desire to drink and learning to live with craving.

5. Develop a party plan. Set a limit on how many drinks you'll have before you go out and stick to it,

6. Don't use alcohol as medicine. Develop alternative means of unwinding, such as meditation, listening to music, radio programmes, watching of films and videos.

7. Eat food containing high proteins before drinking.

8. At a social occasion, have a non-alcoholic beverage to quench your thirst.

\section{Treatment dimension of alcoholism}

Alcohol is a treatable illness as confirmed by a study done for the United States of Alcoholism is a complex problem, 
and each case must be treated with sensitivity and recognition of its unique situation and contributing factors such as individual personality, psychological and sociocultural backgrounds. These must be addressed to help the alcoholics regain control of their life. Alcohol is a treatable illness as confirmed by a study done for the United States of America. The National Institute of Alcohol Abuse and Alcoholism (1999) reported that $70 \%$ of the patients who attended government-supported treatment services recovered. The most common and usual treatment of alcoholic people is the psychological approach. Psychological treatment can be provided either individual or in a group setting. The therapists and patients examine crucial emotional issues that affect the patient's view of the world, his responses, and behaviour.

The most difficult and significant step for an alcoholic is admitting to an alcohol problem. Confrontation, either personal or via an accident or drink-driving conviction that makes the individual acknowledge the alcohol problem is often turning point in seeking abstinence. Recovery from alcoholism is enhanced when the person has strong emotional support system including concerned family, friends and employer.

Some people need what is known as aversion therapy. Aversion therapy is accomplished by giving the person some medicine which cause nausea and vomiting. This medicine is given at about the same time the person takes his favorite alcoholic drink so that an association of alcohol and sickness is created in the patient's mind. This session is repeated every other day until a total of four to six are completed. Every six months, a repeated treatment is administered. Electro-shock techniques are also sometimes used in an aversion therapy. Another important form of treatment involves the use of the drug antabuse (American College Health Association, 2005; Moore, 2009).

Alcoholism treatment programme for the alcoholics as reported by Mukamai (2009), Korolenko and Donrieih (2010) and Wechsler (2011) include managing acute intoxication episode through detoxication and the gradual withdrawal of alcohol in the body; correcting chronic health problems associated with alcoholism and changing long-term alcoholic behaviours. Self-help group programmes such as Alcoholics Anonymous (AA), Rational Recovery (RR), Secular Organizations for Sobriety (SOS) and Women for Sobriety (WS) can offer support to individuals recovering from alcohol problems. Strategies such as the use of culturally appropriate non-stigmatized language, development of supportive case management, implementation of mentoring system, expansion of child care services and creation of multi-media campaign that educate them would assist to build a new alcohol-free life. The use of 28-days treatment programs for in-patient or residential treatment in a medical or psychiatric hospital or a residential faculty are the cornerstones of early recovery treatment.

Outpatient treatment may involve group therapy, individual supportive therapy, marital or family therapy, regular attendance at Alcoholic Anonymous (AA) or another support group, brief interventions and relapse prevention. The brief interventions include individual counseling, group therapy, and training in specific motor-skills within six to eight weeks period, may be most helpful for problem drinkers who are not depend physically on alcohol. Moderation training approach using cognitive behavioural technique would assist problem drinkers who have not become dependent on alcohol to control their alcohol intake; and learning consumption management technique such as never has more than one drink an hour.

\section{Roles of Health Educators about Alcoholism}

A person trained as health educator has a great contribution to make about alcoholism. Health education personnel should play a prominent role in health programme because of their training experience. Health educators should help in educating the public about the moderate use of alcoholic drinks. As regards alcoholism, they should be able to educate students in schools and people in the environment using in-house health talks, debates, lecture, symposium, workshop and clinics about the side-effects of heavy consumption of alcoholic drinks. They could invite other health personnel to talk to both students and the people about the physical, psychological and social problems of alcoholism. The addicts could be counseled by health educators on how to get over the social problem. Mass education on alcohol drinks should be a must and be well organized, planned, coordinate and executed by health educators and supported by the government in power regardless of political affiliations.

\section{Conclusion}

For people with alcohol dependence and abuse, recovery is a lifelong process of change rather than one-time treatment. Through therapy, education, and a re-evaluation of what is meaningful in life, they can find hope for a better way of living. Although relapses are painful, they may serve a purpose in developing the insight and motivation needed to break out of a self-destructive pattern of alcoholics' lifestyle once and for all. Responsible drinking is a matter of you controlling your drinking, rather than the drinking controlling you. Drinking of alcohol to excess, changes human conduct by impairing reasoning, will-power, self-control, judgment, and physical status such endurance, wellness, happiness, mental, stability and in a way may shorten life. The only way to stopping alcoholism is to avoid excessive drinking of alcohol if possible. Drink to moderation is a terrible fallacy. It is therefore important to educate the young about alcoholism towards building a viable and virile society.

\section{Recommendations}

Towards solving the problems of alcoholism, it was 
therefore, recommended that:

1. There should be mass education on alcoholism through public lectures, debates and symposia.

2. People should be encouraged to have non-distilled drinks as their choices.

3. Join the Alcoholics Anonymous group for the treatment of alcoholism.

4. The alcoholics should attend special hospital or medical lectures for the treatment of alcoholism.

5. Health education should be made compulsory in all educational institutions.

\section{References}

[1] American College Health Association (2005). Spring conference group report on alcoholism. Journal of American College Health. 53(5) 199.

[2] Archer, L. (1995). The potential effects on the prevalence of alcohol abuse and dependence. American Journal of Public Health. 85, 1 .

[3] Baer, J. (2004). Effects of college residence on perceived norms for alcohol consumption: An examination of the first year in college. Psychology of Addiction Behaviours. 8, 1 .

[4] Bier, C. (1962). Problems of addiction, alcoholism and narcotics. USA: Fordham University Press.

[5] Briggs, L. A. (2010). Issues in health education. Abuja: Timi Hyacinth Enterprises.

[6] Brewer, R. \& Monica, S. (2006). Binge drinking and violence. Journal of American Medical Association . 294,(5) 616.

[7] Dianne, H. (2007). An invitation to health. United Kingdom: Thomson Wadsworth Corporation.

[8] Fleming, A. (2005).The delightful poison: The use and abuse of alcohol by societies and the social impacts of alcohol for grade 7-12. In Popular Science. China: Grolier International Incorporation.

[9] Granty, F. B. \& Dawson, A. D. (2007). Age at onset of alcohol use and its association with DSM-IV alcohol abuse and dependence. Journal of Substance Abuse. 9, 106-110.

[10] Geddes, S. \& Grossets, S. (2001). Men's health. United kingdom: David Dale House.

[11] Havard, S. (2003). Regular alcohol consumption is good for the heart and circulation. Havard Health Letter.28, (6) 1.

[12] Hussel, C. G.; Fifield, R. J. \& Brimble, L. J. (1998). Anatomy, Physiology and Health. London: Macmillan Education Press.

[13] Jancin, B. (2003). Cardiovascular benefits of alcohol challenged. Family Practice news. 33 (6) 12.

[14] Jane, H. (2010). Teen guide to pregnancy, drug and smoking. London: Aladdin books and West Publishers.
[15] Jones, K. L.; Shainberg, L. W. \& Byer, C. O. (2009). The delightful Poison: The use and abuse of alcohol by society and the social impact of alcohol for grades 7-12. In Popular Science, China: Grolier International Incorporation.

[16] Korolenko, C. P. \& Donrieih, T. A. (2010). Additive behaviour in women: A theoretical perspective. Drug and Society. 4, 3965 .

[17] McCaul, M. \& Janice, F. (1994). Alcoholism treatment in the United States. Alcohol Health \& Research World. 18, 4.

[18] Mintz, L. (2012). Relations among parental alcoholism, eating disorders and substance abuse in college women: Additional evidence against the myth. Journal of Counselling Psychology. 42,1 .

[19] Moore, M. J. (2009). Feasibility and efficacy of a binge drinking prevention intervention for college students. Journal of American College Health 54(1) 38.

[20] Mulamai, K. (2009). Prospective study of alcohol consumption and risks in other adults. Journal of American Medical Association. 289.

[21] National Institute of Alcohol Abuse and Alcoholism (1999). Effects of alcohol consumption on the body systems. NIAAA 443.

[22] Nelson. T. F. (2005). The sate set the race: The relationship of college binge drinking to State binge drinking rate and selected State alcohol control polices. American Journal of Public health. 95 (3) 441-446.

[23] Office of Applied Studies, Substance Abuse and Mental Health Services Administration (2002). Report on the drug and alcohol service information system. Rockville MD: Substance Abuse and Mental Health Service Administration.

[24] Office of Applied Studies, U. S. Department of Health and Human Services (2007). National household survey on drug abuse and alcoholism. Main Findings Report. 106, 110-111.

[25] Wechsler, H. (1994). Health and behavioural consequences of binge drinking in college. Journal of American Medical Association. 272, 21

[26] Wechsler, H. (2011). A gender specific measure of binge drinking among American Youth. Journal of Public Health. 85, 7.

[27] Wetherington, C. L. (2008). Alcoholism and health of women: Executive summary. National Institute of Drug Abuse.NIH Publication 98-4289.

[28] Whitey, A. M.(2009). College students lack knowledge of standard drink volumes: Implications for definitions of risk drinking based on survey data. Alcohol, Clinical and Experimental research 29 (4) 631-633.

[29] Wilsnack, S. C., Vogeltanz, N. D. \& Wasser, A. D. (1997). Childhood sexual abuse and women's substance abuse: National survey findings. Journal of Study on Alcohol. 53 (3) 264-271. 